\title{
0 Teatro do quintal do senhor Baquet
}

\section{Laurinda Ferreira}

\section{A gravura da memória}

Agora disponivel online, em artigos que perpetuam a memória da tragédia nele ocorrida na noite de 20 para 21 de Março de 1888, a gravura original da fachada do Teatro Baquet foi publicada pela primeira vez na revista Arquivo pitoresco (VI de 1863), dando a conhecer ao país o teatro nascido no extenso quintal do Senhor Baquet da rua de Santo António, no Porto ${ }^{1}$. A fachada possui frontão neoclássico e quatro estátuas no cimo, apresentadas pelo Arquivo pitoresco como sendo " a Comédia, a Música, a Pintura e as Artes". Embora critique a escolha da ingreme rua de Santo António - actual 31 de Janeiro - para localização do teatro, esta é apresentada como um lugar seguro e agradável e as figuras representadas parecem apontar a pluralidade dos públicos a que se destinava o espaço.

Desenhada e esculpida em madeira pelo destacado colaborador Nogueira da Silva, para o semanário ilustrado Arquivo pitoresco, esta gravura é exemplo da riqueza do trabalho de ilustração produzido por esta publicação que era, em conjunto com O panorama, "um dos dois principais periódicos literários da primeira metade do século XIX" (Dias 2007: 2) muito contribuindo para o desenvolvimento das artes gráficas - nomeadamente em estratégias editoriais de relação da imagem com a palavra - ao fundar uma escola de gravura, que Nogueira da Silva dirigia.

Transmitindo a ideologia e os valores dominantes em Portugal e no Brasil, em artigos que pretendia informativos e educativos, por vezes distribuídos nas escolas, o Arquivo pitoresco tentava acompanhar o ritmo dos acontecimentos sociais a nivel regional, nacional e internacional. É neste contexto que surge publicado, quatro anos depois da sua inauguração, o artigo sobre o Teatro Baquet.

No corpo do artigo, a publicação refere a beleza do teatro e elogia o proprietário que dotou o Porto de um teatro de declamação, satisfazendo "uma necessidade, porquanto não tinham as companhias dramáticas portuguesas onde representassem dignamente, a não ser no Teatro S. João, alternando-se com as companhias italianas de ópera lírica" e considera este último teatro pouco adaptado ao teatro de declamação, o que tornava o Baquet absolutamente indispensável.
Depois de datar o início das obras em 22 de Fevereiro de 1858, refere as dificuldades de construção "porque a rua de Santo António está na altura de mais de um terceiro andar em relação ao terreno onde se abriram os alicerces do edifício", tendo sido necessário construir "um grande prédio, que se compõe de armazéns e andares, com portas e janelas para a Viela da Neta" ${ }^{2 n}$, que Ihe servisse de suporte. Refere, de seguida, que o Teatro foi inaugurado a 13 de Fevereiro de 1859, no carnaval, com o baile de máscaras, "a que concorreu toda a sociedade elegante do Porto" (Filinto 1888: 9) e que a "inauguração solene, depois de concluídas todas as obras de ornamentação, [se] realizou em 16 de Julho de 1859 com a apresentação da comédia drama - O segredo de uma família - original do sr. José Carlos dos Santos ${ }^{3}$ e desempenhada pela companhia de Teatro do Gynásio de Lisboa". Atribui o desenho da fachada, "construída da melhor qualidade de granito em que abundam os arrabaldes da cidade", ao "Sr. Guilherme Correia" e revela ter sido a "planta do resto do edifício [feita pelo] próprio Sr. Baquet", os trabalhos de pintura do interior pelo "sr. João José Faria Teibes" e os de "doiradura pelo Sr. Rossi".

Considera que a sala "não é falta de elegância, e achase decorada com singeleza e bom gosto", contando com "82 camarotes repartidos por quatro ordens, incluindo as galerias e varandas, que acomodam duzentas pessoas". Escreve ainda que a "plateia superior tem 178 lugares, e a geral 236 e tem graves defeitos acústicos", com a consequente dificuldade de audição em alguns dos lugares, revelando que o montante despendido pelo sr. Baquet na construção do Teatro tinha sido de "cinquenta contos de reis".

Relativamente ao número de camarotes, as palavras de Jayme Filinto (1888: 14), são divergentes. Este autor refere oitenta e quatro camarotes originais que, por demasiado estreitos, serão reduzidos em quatro, por cada ordem. Na terceira ordem, também os quatro camarotes de frente foram transformados numa varanda. Destas alterações resultaram os vinte e quatro camarotes nas duas primeiras ordens e apenas vinte na terceira, num total de sessenta e oito.
Ver aqui, p. 123

2 Esta rua, hoje desaparecida, é descrita no artigo "Será que vai desaparecer o que resta da Viela da Neta?" do Jornal de notícias de 11 de Julho de 2004 (recolhido a 11 de Janeiro de 2012, em

http://www.jn.pt/paginai nicial/interior.aspx?con ent_id $=450041$ \&tpage $=2$

3 José Carlos dos Santos (1833-1886), mais

conhecido por Santos Pitorra (Rigaud 2009:18).

Laurinda Ferreira é actriz e mestranda em Estudos de Teatro pela Faculdade de Letras da Universidade de Lisboa. 
Maqueta da rua 31 de Janeiro, Porto.

Corte Teatro Baquet.

Planta Baquet (fonte:

OPSIS, base de dados do

Centro de Estudos de

Teatro da FLUL).

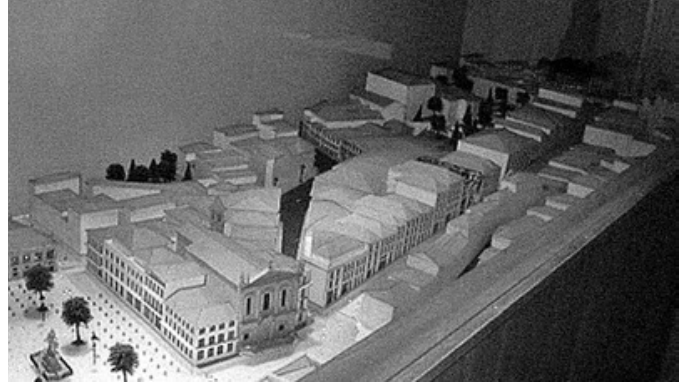

\section{Um homem empreendedor}

Em 1828 o portuense António Pereira, ainda adolescente, emigrou para Espanha com toda a família, para regressar a Portugal, em 1836, casado com D. Ignácia de la Bica e exercendo a arte de alfaiate que the proporcionou, em quatro anos, a sua própria alfaiataria. Em 1857, depois de várias estadias no estrangeiro, regressa de Paris com o misterioso apelido Baquet, supõe-se que para dar prestígio ao seu atelier, numa rua em que todos os estabelecimentos usaram a mesma estratégia. Depois desta adição foi sempre considerado francês, ou espanhol, com o apoio da estranha pronúncia que, entretanto, adquirira.

Este homem arrojado funda a primeira loja de prontoa-vestir da cidade, no número 157 da rua de Santo António e inicia, ao lado, a construção de um teatro, num extenso quintal de que é proprietário, um pouco abaixo do Teatro Circo (mais tarde Principe Real). As obras de construção duram menos de um ano, prazo estranhamente curto para uma obra de tal dimensão, uma vez que o teatro assenta no prédio de três andares e que teve de ser construído, na base, "um grande armazém em arcos de pedra" que o sustentasse, nivelando, assim, a altura das traseiras do quintal, que iam até à rua de Sá da Bandeira. Jayme Filinto, em A grande catástrofe, descreve com detalhe a noite de estreia:

A inauguração foi num domingo. Durante todo o dia o edificio estivera embandeirado, anunciando a festa. À noite a fachada iluminou copinhos, e no átrio tocou a banda de música do 5 d'infantaria. Dentro do teatro não se sabia qual admirar mais [...], se as belezas que tão acordes se sustentavam na construção de ornatos, se o facto fenomenal de que tudo aquilo se fizesse como por encanto, num curto espaço de 11 meses, pela força de vontade e corajosa perseverança de um só homem! 160 lumes do magnífico lustre, com os 20 lumes dos candelabros do proscénio, produziam uma iluminação a giorno, que fazia sobressair as belezas do conjunto. (Filinto 1888: 11)

Ainda assim, refere o autor, a afluência não foi a esperada na inauguração de um teatro, facto que justifica com a pacatez dos hábitos dos portuenses, "que se deitavam com as galinhas" e se levantavam com o canto do galo, pouco consentâneos com a presença em bailes de máscaras em véspera de dia de trabalho, com a agravante da concorrência de um outro baile mais acima, no Teatro Circo, e outro no São João, também ressentidos com a inauguração da casa da Assembleia Portuense, no largo da Trindade.

0 autor continua a sua descrição com o salão do primeiro andar do edifício, ao nível da terceira ordem, formado por "três salas, abertas em arco, e iluminadas cada uma com o seu elegante candelabro suspenso", o
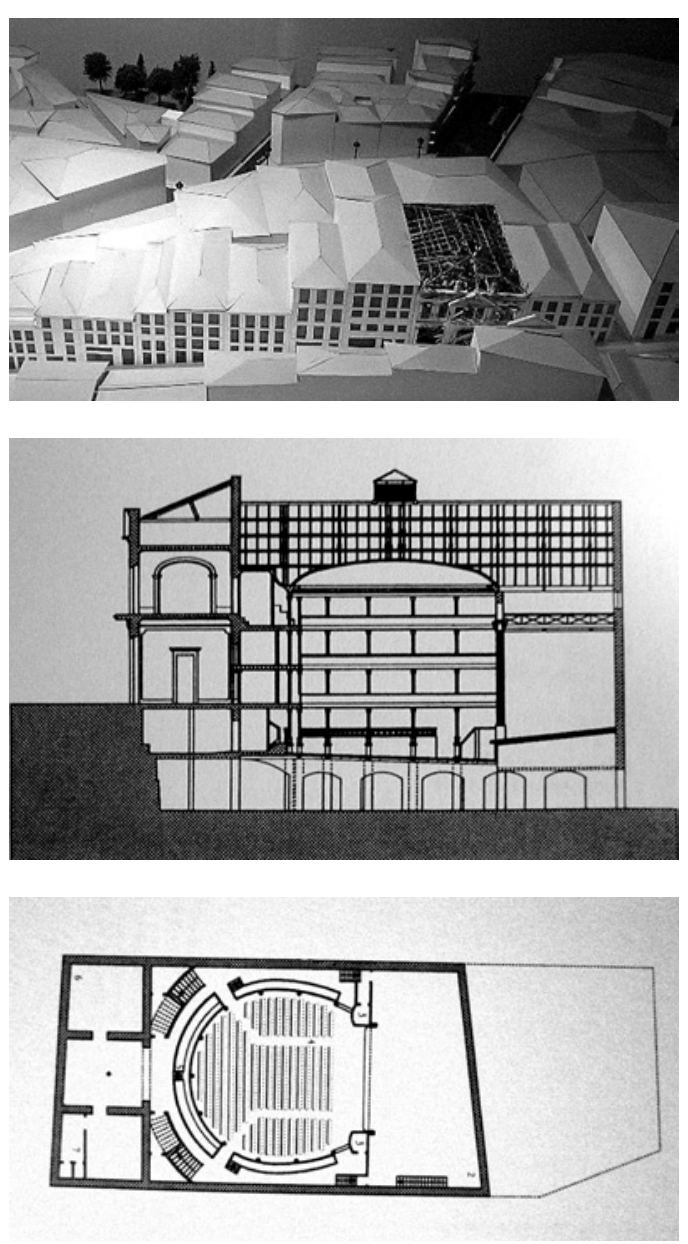

que nos permite compreender que a sala de espectáculos ficava rebaixada um andar, relativamente à rua de Santo António.

As festividades prolongaram-se pelos três dias de Entrudo, com uma orquestra organizada com músicos do teatro lírico, regidos pelo professor Medina de Paiva e, dos foliões presentes nos vários bailes na terça-feira gorda couberam trinta e seis ao teatro Circo, oito ao Baquet e cinco ao Teatro São João, falhanço a que não terá sido alheio o excessivo preço de 2.250 réis dos camarotes da primeira e segunda ordens do Teatro Baquet, segundo Jayme Filinto (1888: 14)

A inauguração solene realizou-se no sábado, 16 de Julho de1859, e a apresentação da comédia-drama 0 segredo de uma familia decorreu com a presença "do que no Porto havia de mais selecto" (Ibid.: 19). 0 pano de boca e o proscénio estavam cobertos com panos, que foram retirados pouco antes de começar o espectáculo para que o público pudesse admirar as pinturas. 0 proscénio era cópia do executado para o Teatro São João pelo pintor Rocha, que foi também autor do pano de boca que, "muito bem perspectivado, representava um varandim com duas cortinas apanhadas, deixando ver parte da antiga rua Ferreira Borges com os edifícios do Banco Comercial, a Bolsa e ao fundo a igreja de S. Nicolau", tema que liga o teatro ao real e à cidade. As cadeiras da plateia - colocadas depois do baile de carnaval - foram alvo de crítica, por serem pouco confortáveis, e são referidas, para além dos camarotes e das duas plateias, a existência de uma galeria, "por baixo da 1ª. Ordem, circundando as duas plateias", 


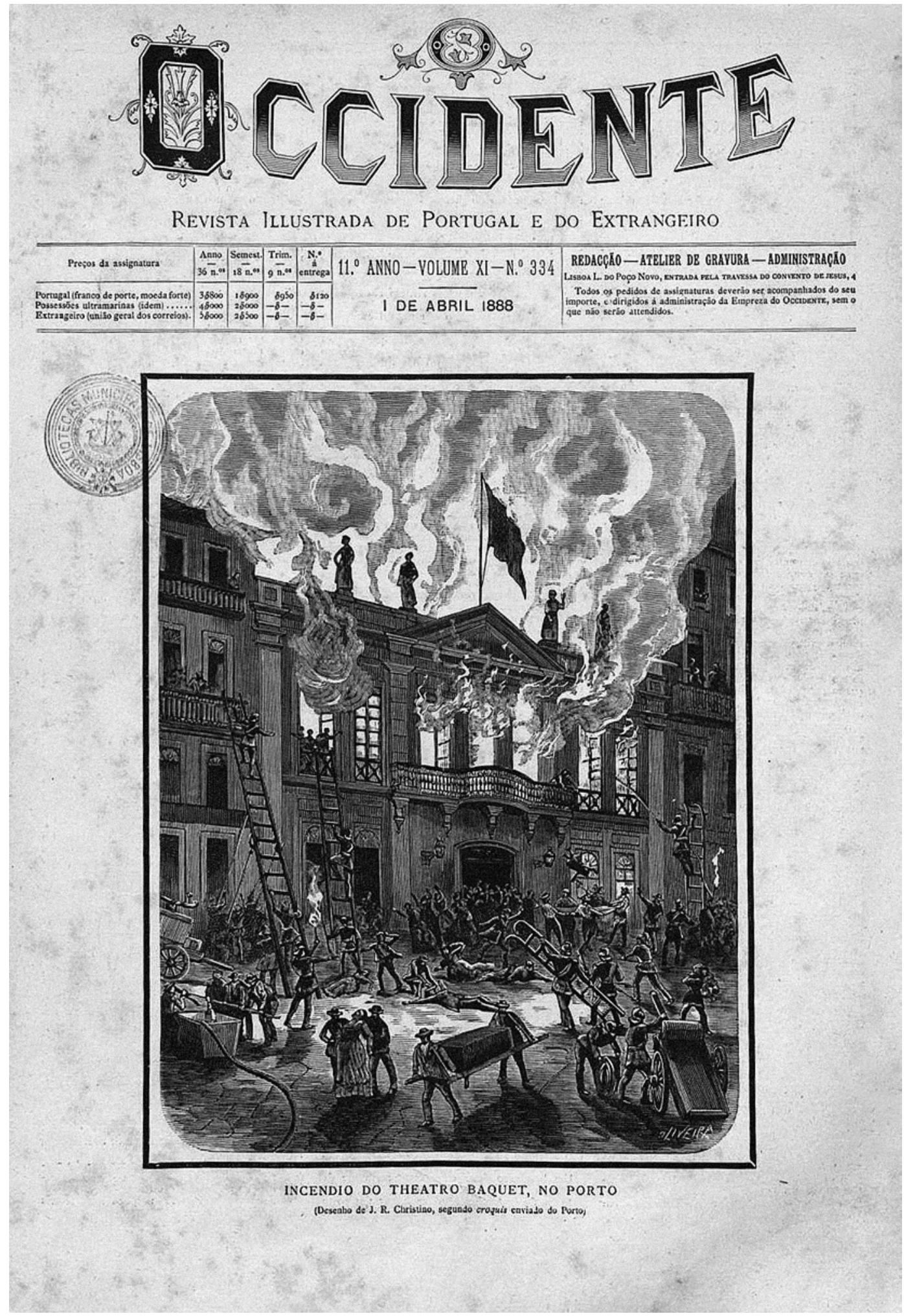

Revista Ocidente

duas frisas de cada lado da ribalta - "uma espécie de baignoires dos teatros franceses" -, as galerias e varandas, que alojavam cerca de duzentas pessoas, para além do facto de os camarins dos artistas e do restante pessoal se situarem por baixo do palco.

Com a remodelação empreendida depois da morte de Baquet, em que, por questões de segurança, será aberta uma saída par a rua de Sá da Bandeira, este pano será posto de lado e substituido por uma vista do "monte do velho seminário, vendo-se a antiga casa do bispo, a fábrica de sabão Roriz e o palácio do Freixo", com o rio ao fundo. Para além deste pano, existia também um pano com anúncios que, certamente, seria mais uma forma de angariação de fundos.

0 tecto foi pintado "a fresco [...] fingindo um grande envasamento de renda, muito elegante", mas foi alvo de críticas na festa de inauguração, por não ter sido decorado por Hercules Lambertini, pintor e cenógrafo de origem 
italiana. Os parapeitos da primeira ordem eram ornamentados com cabeças de satyros e tinham pintados, em letras encarnadas, com fundos dourados, os nomes de: Cervantes, Calderon, Quintana, Alfieri, Shakespeare, Corneille, Rossini, Schiller, Mozart, Auber, Moliére, Gil Vicente, Garrett e Camões", revelando, talvez, a vontade de levar à cena grandes autores do Teatro e da Música, por parte do viajado proprietário.

A comédia-drama em três actos foi "delirantemente aplaudida", destacando-se José Carlos Santos no papel de Visconde S. Pedro e Marcolino no de José Bento. 0 reportório apresentado pela companhia no Teatro Baquet - detalhadamente referido por Jayme Filinto - era maioritariamente constituido por comédias, integrando ainda dois dramas, várias poesias e "cenas cómicas" e a opereta Tio Brás - arranjo de Mendes Leal com base na opereta de Offenbach - em que estreia o actor Simões. Agendada para o dia seguinte à inauguração, a repetição da apresentação de Segredos de uma familia, a mesma foi adiada uma semana, devido ao luto obrigatório por morte da Rainha D. Estefânia. A presença da companhia no Baquet durou exactamente um mês e terminou com a apresentação de Probidade, cena cómica pelo actor Simões e Senhor José do Capote assistindo à representação do Trovador, cena cómica por Taborda, a 16 de Agosto 4 . A companhia regressou depois a Lisboa, "parte na malaposta e parte no vapor Lusitânia".

A propósito das instalações, o Eco popular, citado por Filinto (Ibid.: 20) elogia a "boa sala de pintar, como não há em S. João, [...] as cenas não têm de ser conduzidas para o palco depois de pintadas, por alguma escada ingreme [...] porque a sala de que falamos tem comodidades para isso; [...] numerosos camarins, com um bom mecanismo para correr as cenas, como o S. João não tem e [...] um palco, cujas tábuas estão postas do melhor modo e com a melhor conveniência, para serem imediatamente tiradas, se a letra de alguma peça [...] ordenar o aparecimento de algum espectro". 0 mesmo periódico elogia, ainda o engenho, o cuidado da construção e a solidez do Teatro.

\section{Poucas raizes e frutos pouco brilhantes}

0 Teatro Baquet passou longos anos sem companhia própria. Só a partir de 1870, na posse da empresa Moutinho, passou a funcionar com maior regularidade. Até então, apenas foi visitado por companhias ambulantes, que pouco lucro tiraram das representações, para as quais arrendavam - Teatro. 0 ensaiador da companhia - que introduziu no Porto o género da opereta cantada por companhias portuguesas, com a opereta Joana do Arco, que tinha letra de Alfredo de Atayde e música de Gomes Cardin - era o actor Romão, substituido, após a sua morte, por Augusto Garraio (Ibid.: 23-24)
Falida a empresa, organizaram-se em sociedade os actores Gama, Soller, Amaral e Domingos d'Almeida, com o patrocínio do Senhor Manuel Vieira d'Andrade e com o reforço dos actores do Trindade que ficaram sem trabalho, devido ao incêndio neste Teatro em 1875. Esta companhia, de que era fiscal José Maria da Costa, desaparece em 1877 devido aos maus resultados financeiros. Em Abril do mesmo ano entra em cena a empresa A. Portugal \& $C^{a}$, constituída pelo tenor Portugal e os senhores Freitas \& Azevedo, que não obteve melhores resultados, sendo substituída por um colectivo de actores e pelo jornalista Borges d'Avelar

A debandada, para o Príncipe Real, dos melhores elementos para integrar a companhia de opereta que a empresa Freitas \&t Azevedo ali fundou, levou à reorganização da companhia, sob a direcção do actor Apolinário de Azevedo, mas com uma época para esquecer. Seguiu-se-Ihe a empresa da actriz Emilia Adelaide que, mais uma vez, não teve bons resultados e, à falência, segue-se a fuga da empresária e a reorganização dos actores em sociedade, passando o elenco a ser ensaiado por J. Romano. Seguiu-se-Ihe outra sociedade de actores, ensaiada por Amaral, com reposição dos textos anteriores e a estreia do drama 0 médico das crianças, até que toma conta do espaço a empresa Perry, já com obras de melhoramento e a construção de uma segunda fachada para a rua de Sá da Bandeira. Novamente com prejuízo, a empresa chega ao seu término em Março de 1887.

Em Setembro do mesmo ano, o espaço é alugado, pela importância de $3.600 \$ 000$ réis, ao empresário Cyriaco de Cardoso, que nele estreou a opereta Mão e coração de Nuitter e Beaumont, traduzida por Luis de Magalhães, a que se seguiram as óperas cómicas Moleiro de Alcalá, Dragões de Villars - um grande êxito -, Giroflé-giroflá, Jovem Telémaco, Grand-via e Chouriços e polacos, para além da comédia Sociedade onde a gente se diverte, de Pailleron. 0 maestro reuniu à sua volta os seguintes actores: Dorinda Rodrigues, Aurélia dos Santos, Amélia Garraio, Teresa Prata, Elvira Mendes, Virgínia Nery e os discípulos Moysés Bensaúde, Firmino A. Rosa, Sanches Mula, Xavier Vieira, Prata, César e Jesuino Sequeira, ensaiados pelo actor Augusto de Melo e, quando este abandona o projecto e se muda para o Príncipe Real, por Borges d'Avelar e Borges d'Almeida. Com esta companhia o Teatro Baquet conhece finalmente um êxito consistente, cimentado por um "notável renascimento artístico, implantando no público a ideia do melhor e educandoos no principio do bom gosto musical". (Ibid.: 27-29)

A estreia da comédia de Labiche Doit-on-le-dire?, traduzida pelos jornalistas Álvaro de Castro Neves e Hamilton de Atavio, com o título de Dir-se-há?, programada para 22-03-1888, não chegou a realizar-se. Na noite anterior um incêndio destrói irremediavelmente o Teatro Baquet e o sonho do alfaiate, entretanto também já desaparecido. 

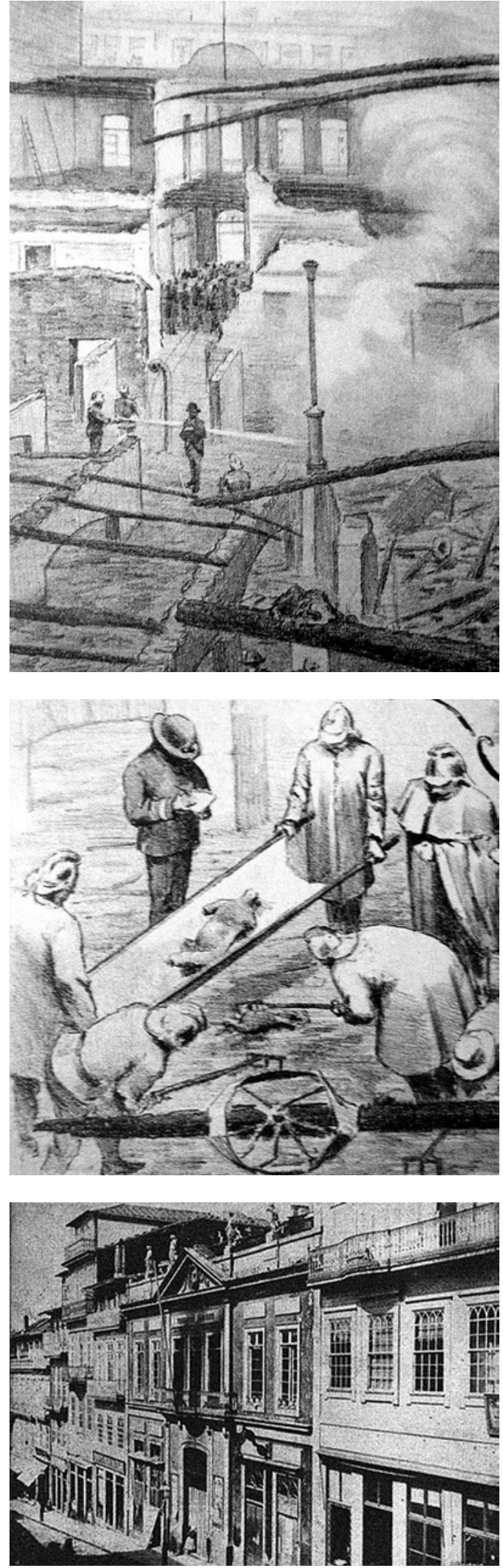

0 remendado Teatro Baquet

António Pereira Baquet faleceu em 1869 e foi sua herdeira a esposa D. Ignácia, que legou a herança a António Teixeira de Assis, ex-sócio do marido, com quem, entretanto, casara. Por morte deste, os bens passaram para as mãos de sua mãe, D. Anna Victória d'Ascensão, residente em Lamego.

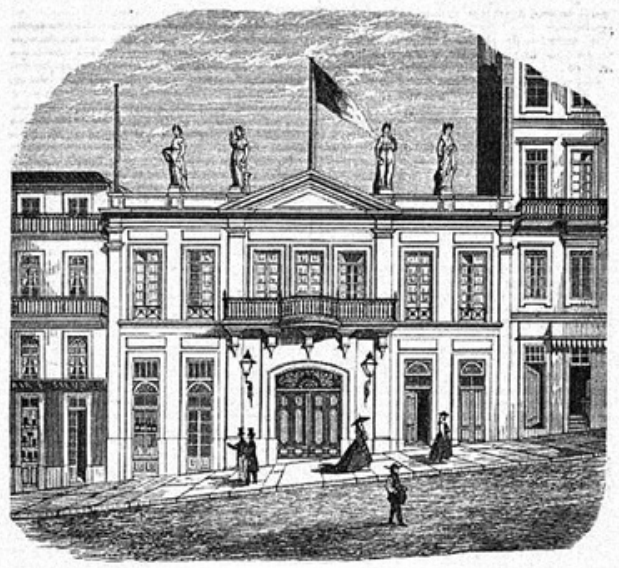

Teatro Baquet (Porto 1863): gravura de Nogueira da Silva (Arquivo pitoresco, $v$. $V I, 1863: 257)$.

A avançada idade e a distância da cidade do Porto levaram a que entregasse as tarefas necessárias ao bom andamento dos seus negócios nas mãos do solicitador Joaquim Ferreira da Costa Guimarães, substituído depois pelo Reverendo Eusébio Rodrigues Cardoso, cantor na Sé catedral. 0 Teatro foi passando, sucessivamente, para a exploração de múltiplos empresários, até chegar às mãos do maestro Cyriaco de Cardoso.

Na já referida reforma de 1887, empreendida pelo (também) viajado herdeiro da viúva Baquet - António Teixeira de Assis -, foi posta de lado uma serventia escusa para "um corredor estreito, entre a porta de orquestra e os camarins", servida por uma escada de madeira, que ia dar a "um saguão que desaguava na antiga Viela da Neta", passando a ser usada a nova saída para a Rua de Sá da Bandeira, para além da original entrada da rua de Santo António, situada onde hoje (2012) se encontra a Caixa Geral de Depósitos. Os camarins passaram para o fundo do palco, roubando-Ihe alguma dimensão, e foram acrescentadas, por cima destes, duas galerias em madeira com mais duas ordens que alojavam os restantes artistas e demais pessoal, a última das quais comunicava com o urdimento. Os antigos camarins, por baixo do palco, passaram a ser utilizados pelos comparsas. Por baixo do palco, ao nível da Rua de Sá da Bandeira, localizavam-se os armazéns e casas de banho do pessoal, com saída para a referida viela. No piso superior da Rua de Santo António situava-se o guarda-roupa e o atelier de costura, por ter sido o espaço considerado demasiado exíguo como salão de pinturas, havendo a ideia de construir outro por cima do urdimento, razão pela qual as pinturas que o cenógrafo Júlio C. Machado executou para as últimas peças foram produzidas em espaços alugados. Na saída para Sá da Bandeira foi construído um gabinete para o empresário, uma sala de ensaios e a arrecadação dos adereços. Havia planos para modificações mais radicais, que implicavam a mudança do palco para a saída da Rua de Santo António, mas não chegaram a ser executadas.

\section{No lugar do riso nasce a catástrofe}

Na noite de 20 para 21 de Março de 1888, depois do cortejo fúnebre do actor Augusto Marques Pinto, realizou-se no teatro Baquet um extenso espectáculo, em benefício do actor Firmino António Rosa, a que o público acorreu em massa, embora a sala não tivesse esgotado. Do espectáculo faziam parte a ópera cómica Os dragões de Villars, de
Imagens da tragédia publicadas em periódicos da época.

Teatro Baquet depois do incêndio. 


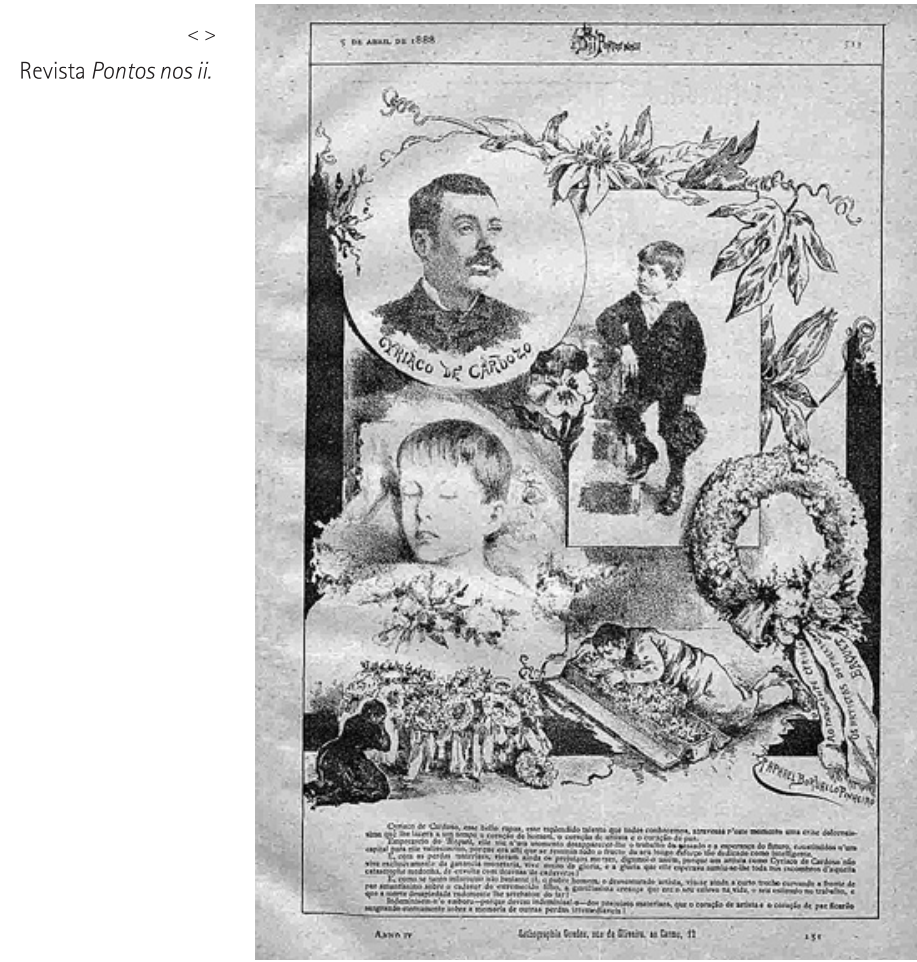

Lockroy e Cormon, em tradução de Borges d'Avelar e Jayme de Séguier, com música do maestro Maillart; um bailado espanhol, pelo corpo de baile e a zarzuela Grand-via de Chueca e Valverde, ensaiada apenas em seis dias, periodo em que também foi feita a adaptação de Guedes de Oliveira.

0 espectáculo Os dragões de Villars tinha corrido bem e o público tinha aplaudido de pé" nos finais de acto". Alguns espectadores saíram e o bailado espanhol que se seguiu teve de bisar. No intervalo, por volta da meia-noite, mais alguns espectadores abandonaram o espaço. A Grandvia, que parodiava a abertura de grandes vias na cidade do Porto, teve então o seu início, sempre acompanhada pelo entusiasmo ruidoso do público. "Os três ratas" era o título do terceiro quadro - traduzido para português por "Os três gajos" -, desempenhado pelos actores Mariano Sanches, Gomes e Firmino Rosa, em frente ao pano de fundo que figurava o edifício da Caixa Filial do Banco de Portugal. No final do quadro, o público exigiu novamente bis de forma ruidosa e persistente e foi executada a contramutação para repor o cenário d'A Grand-via, que tinha subido à teia. (Filinto 1888: 35)

Já o maestro Cyríaco Cardoso tinha regido os primeiros acordes quando o pano de fundo desceu novamente, agora de forma brusca, deixando-o de braços no ar. Logo de seguida, era possível perceber uma grande azáfama no palco - a que a maior parte dos espectadores não prestou atenção, pois aumentou a veemência com que pedia bis - e o pano de boca fechou precipitadamente, não sem que alguns espectadores mais atentos percebessem que havia um pano a arder junto a uma gambiarra e que algumas faúlhas caíam no palco. Mas a maioria continuava ruidosamente a exigir bis e interpretou a descida dos panos como erro de contra-regra. Uns ficaram a ver sossegadamente, outros pateavam risonhamente, como forma de protesto. Cyriaco de Cardoso, percebendo o que aconteceu, colocou o chapéu e manteve-se no seu posto para reger as saídas. Nesta altura, os ocupantes do camarote 24 tinham já visto que

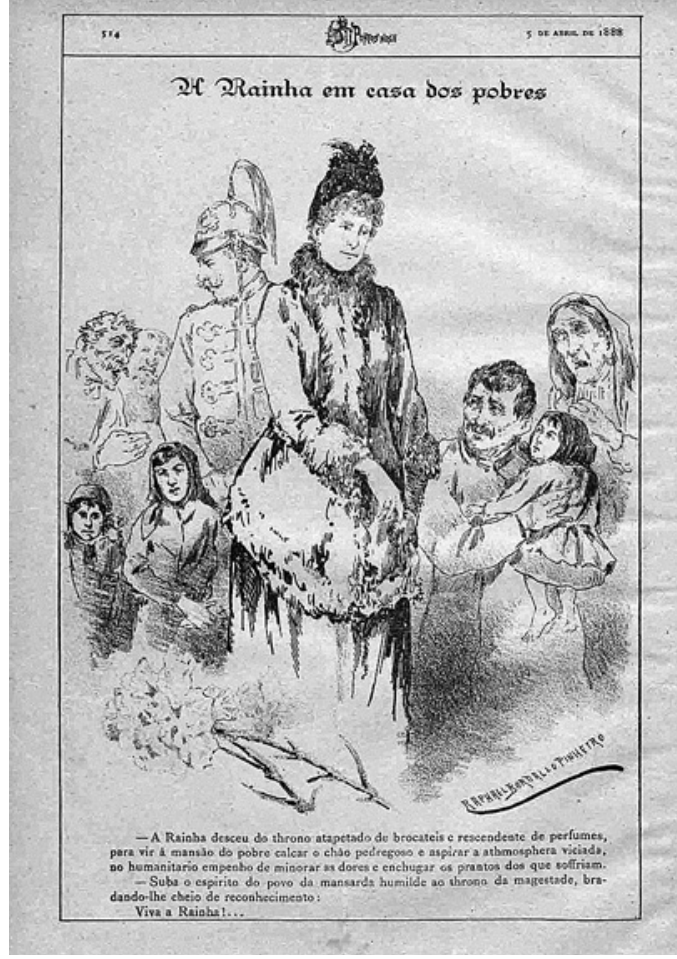

o urdimento ardia com intensidade, através de um postigo que dava directamente para o palco e saíram precipitadamente. Foi o grito de "fogo!" de um deles que deu o alerta à plateia, que entrou em pânico, substituindo a máscara do riso pela do terror. 0 maestro Cyríaco, com grande sangue frio, tentou acalmar a multidão e pediuIhes que saissem com calma e devagar, que não havia motivo para preocupações. Os ocupantes da plateia obedeceram, mas nos camarotes e na galeria as senhoras romperam em gritos e algumas desmaiaram. Alguns espectadores das galerias saltaram para a plateia; nas varandas o povo apinhado tentou salvar-se saindo tumultuosamente, enquanto um fumo espesso invadia a zona da terceira ordem, através da bambolina do pano de boca que, entretanto, começara a enfunar. Foi no auge destas fugas desesperadas que foi desligado o gás, deixando tudo às escuras, uma vez que, devido à extensão do espectáculo, a iluminação de recurso estava já extinta.

0 pano de boca começou a ser consumido pelas chamas, que fluiam para à única saída de ar, situada no tecto, e acabou por rasgar ao meio, caindo, parte dele, entre a ribalta e a orquestra, levando ao alastrar rápido do fogo à plateia e ao pavimento por debaixo do palco. Os espectadores, em pânico, atropelaram-se uns aos outros. Os que subiram as escadas para a saída da Rua de Santo António esbarraram com os que desciam das ordens superiores que, às escuras, não deram com a saída. Muitos, sufocados pelo fumo, cairam inanimados, formatando montes humanos e impedindo os ainda conscientes de encontrar as saidas. Alguns dos que conseguiram sair voltaram a entrar, para tentar salvar alguém. Outros, chegavam cá fora e percebiam que a mão que traziam agarrada à sua não era dum familiar e voltavam para o tentar resgatar, acabando por Ihe fazer companhia na imensa fornalha em que o Teatro Baquet se transformou rapidamente. Em menos de duas horas, do belissimo Teatro Baquet, restavam apenas as quatro escalavradas paredes exteriores. 


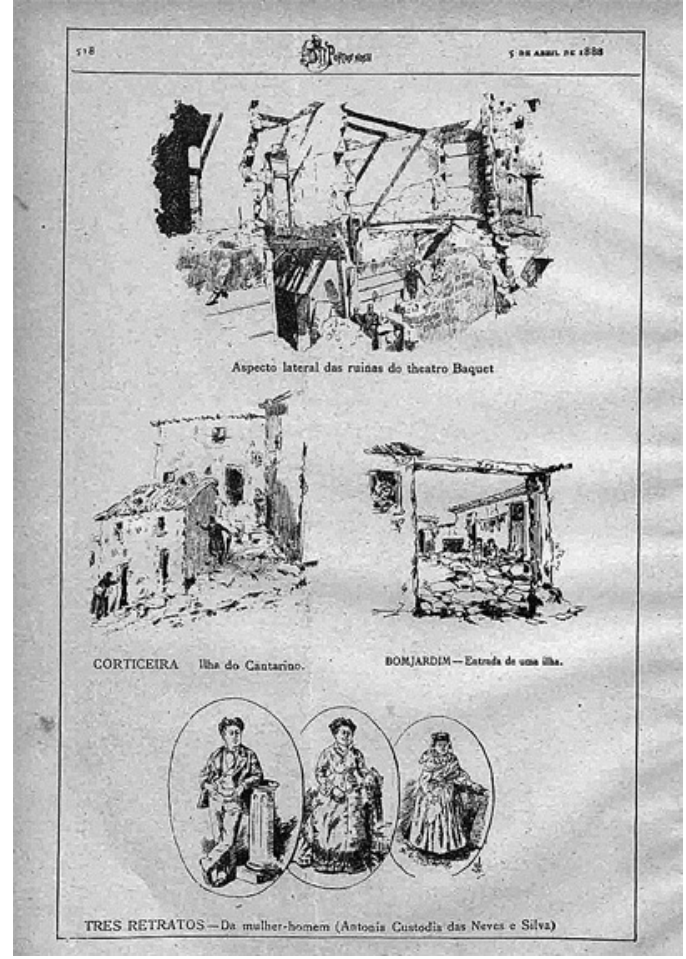

\section{Os frutos da incúria}

Tudo o que podia correr mal, na noite de 20 para 21 de Março de 1888, aconteceu. 0 incêndio foi provocado por um dos muitíssimos panos pintados, suspensos da teia e enfileirados "no urdimento, uns sobre os outros, quase embaraçando as manobras dos maquinistas" (Filinto 1888: 49). Na manobra executada para descer o pano da GrandVia, uma das bambolinas, que ficava muito próxima de uma gambiarra, oscilou. Devido à exiguidade do espaço necessário para boas práticas, e como a bambolina estava "esfiapada ", um dos fios prendeu-se numa das malhas da rede de protecção da gambiarra e incendiou-se num dos bicos de gás. Esta rede não evitava problemas deste tipo, pelo que deveria ter sido usada uma "telha metálica" (Ibid.), por cima dela.

Os maquinistas aperceberam-se imediatamente do problema, mas não tinham consigo as navalhas, de que habitualmente se muniam, e que teriam permitido cortar as cordas e arriar o pano que ardia. 0 bombeiro municipal que estava de serviço ao palco gritou que cortassem a corda e, mal o pano de boca caiu, fugiu. 0 aspirante, que estava no urdimento, correu para a boca-de-incêndio, mas a mangueira estava enredada - deitando apenas um pequeno jacto - e acabou por rebentar.

Os artistas - na roupa das personagens - e os empregados do Teatro corriam desesperados nos bastidores, tentando encontrar os filhos e outros familiares que os acompanhavam, enquanto, no palco, os panos (pintados com aguarrás) propagavam rapidamente entre si as chamas que alastraram a todo o espaço do Teatro. Exceptuando a costureira espanhola Abelarda Rodrigues e a ex-corista Adelaide, que adormecera num dos camarins de terceira ordem, todos os que estavam na caixa do palco se salvaram, graças à antiga saída da Viela da Neta, entretanto desactivada.

Cyriaco de Cardoso foi o último a abandonar o Teatro, convencido de que todos se tinham salvo. No dia 20 tinha

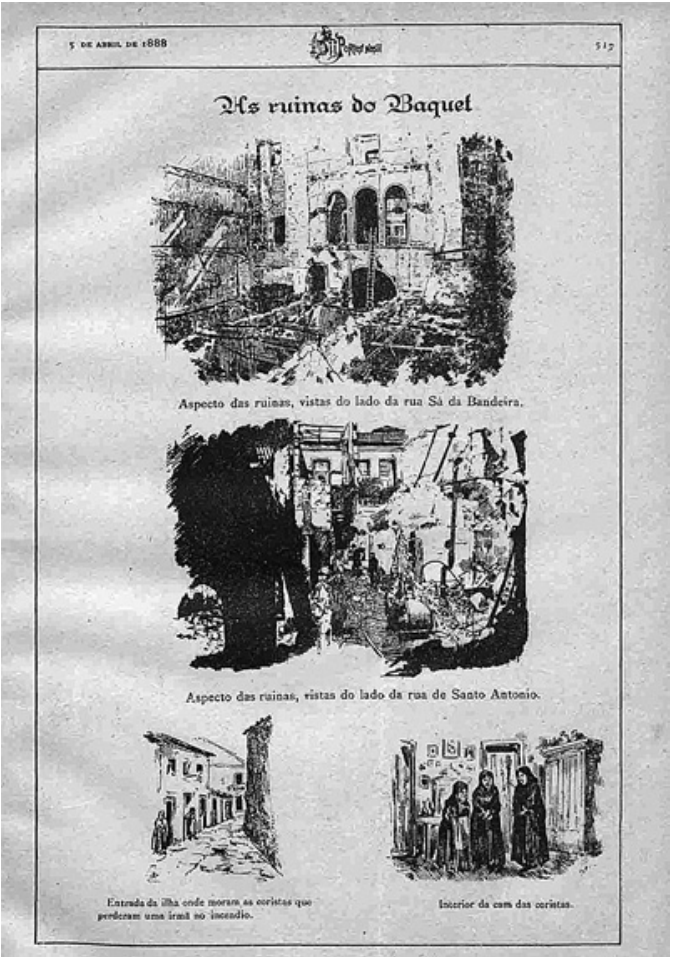

Revista Pontos nos it

tido uma reunião marcada com um representante de uma seguradora, para segurar todo o material da sua empresa no espaço do Baquet - guarda-roupa, partituras, adereços, cenários, etc. -, que adiou para poder prestar a última homenagem ao actor Augusto Marques Pinto, pelo que ficou na rua a ver arder todo o fruto do trabalho da sua empresa. Arruinado, restava-Ihe a consolação de pensar que ninguém tinha morrido.

Este equivoco deveu-se a vários factores. Ao mesmo tempo que as fugas bem sucedidas se efectuaram pela Rua de Sá da Bandeira, foi também aí que os bombeiros acorreram inicialmente, já com grande atraso. As razões desta demora são de tal forma inacreditáveis que transcrevo o que sobre isso foi escrito na revista Ocidente (01-041888: 76):

Um espectador, logo que começou o fogo, dirigiu-se à estação da bomba dos Paços do Concelho, pedindo socorros, mas foi-Ihe respondido que nem a bomba nem o material saiam sem haver toque de incêndio. 0 bombeiro que deu tão estúpida resposta já foi suspenso

e naturalmente será punido. Quando se ia dar o sinal de incêndio nas torres da Igreja dos Congregados e Santo Ildefonso, as cordas partiram, provindo disso também a morosidade da chegada dos socorros públicos. (apud Filinto 1888: 58)

A este propósito, Filinto refere que a primeira bomba que chegou à Rua de Sá da Bandeira foi "uma bomba puxada à mão" dos bombeiros voluntários, seguida, algum tempo depois, do material das corporações municipais, que começaram a atacar o fogo na Rua de Sá da Bandeira e, apenas quinze minutos depois, foram informados por alguém que dera a volta para pedir socorros, de que na saída para a rua de Santo António havia "corpos aos montões e se passavam cenas perfeitamente horrorosas" (lbid.).

Era demasiado tarde, pois aquela era a entrada principal, onde a maioria dos cadáveres se amontoaram. 
Uma das razões para esta mortandade foi o facto de as portas do salão do primeiro andar se encontrarem já fechadas. Se algumas das pessoas sobreviveram foi porque chegaram ao telhado e pediram ajuda pelas janelas dos prédios vizinhos. Todas as pessoas que desceram, tentando a saida para Sá da Bandeira, tiveram a dificuldade acrescida de corredores escuros, pois não tinham uma saída directa para a rua, razão principal da necessidade de alterar a sala, colocando o palco na saída de Santo António. Esta obra, que podia ter permitido ter "luz ao fundo do túnel" para saída dos espectadores, não foi realizada por conflito judicial com o inquilino do espaço do café High-life.

\section{De más sementes crescem maus frutos}

Esta soma de contratempos é encarada por Jayme Filinto como uma conjugação de factores de sorte adversa, que leva à tragédia. Mas os deuses em pouco contribuíram para um desfecho que a incúria de muitos homens provocou. É sobretudo relevante a leviandade com que era encarado o perigo a que se expunham todos os que frequentavam os espaços de apresentação de espectáculos. "A maior parte das obras de segurança que a autoridade havia ordenado, segundo um relatório feito há meses pelo inspector-geral dos incêndios, não tinham sido cumpridas" (Ocidente 01-04-1888: 76). E não foi por falta de aviso, ou exemplo, como se pôde ver no artigo "Crónica Ocidental" de Gervásio Lobato:

\footnotetext{
Desde o primeiro germinal do ano VII uma lei exigia aos teatros da França condições severissimas, que nunca foram observadas, não observância que motivou em Janeiro de 1838 o incêndio do Teatro Italiano, e dali a meses, em Julho, o incêndio do Teatro de Vaudeville, exactamente como agora no Baquet a falta de cumprimento das prescrições, feitas há um ano, pelo inspector dos incêndios, contribuiu enormemente para a grande catástrofe que hoje enluta a segunda cidade de Portugal. (Lobato 1888: 74)
}

0 mesmo artigo contém uma lista dos incêndios em espaços públicos de espectáculos (teatros e circos) ocorridos entre Junho de 1836 e 1888, que montam a 23 . Apenas em 11 meses do ano de 1887 ocorreram dez incêndios com 798 vítimas mortais, o que demonstra uma incúria crescente, com a respectiva factura paga em vidas humanas. 0 próprio Baquet tinha já tido três princípios de incêndio, de que não resultaram vítimas, mas que levou à relutância de alguns espectadores em frequentar 0 espaço.

\section{Enterrados os mortos, resta uma ferida}

\section{na memória da cidade}

Foi impossível contar os mortos, pois só foram encontrados pedaços irreconheciveis dos cerca de cento e vinte, contabilizados pelas investigações jornalísticas, enquanto da lista oficial apenas constavam oitenta e oito. 0 actor Firmino perdeu quatro familiares no incêndio e o Maestro Cyriaco de Cardoso perdeu o filho, ainda criança ${ }^{5}$. Órfãos e famílias desfeitas e/ou arruinadas foram a face mais explorada pela imprensa, num movimento nacional com vista a angariar fundos que os confortassem, no que aos bens materiais dizia respeito. A rainha Dona Maria Pia deslocou-se ao Porto, e o mesmo fizeram muitos dos artistas que foram de Lisboa, para participar no espectáculo organizado pela imprensa para angariação de fundos, que se realizou, em matinée, no dia 25 de Março de 1888, no Palácio de Cristal.

Os jornais encheram-se de gravuras demasiadamente explícitas e as descrições dos horrores daquela noite não deixam ninguém indiferente. São retratadas as várias fases do incêndio, a visita às ruínas depois de extinto o incêndio, a visita da rainha aos casebres de bairros miseráveis do Porto e as visitas ao necrotério improvisado no cemitério de Agramonte, onde se tentou reconhecer ou homenagear pedaços de corpos que, devido à exiguidade do espaço, estavam expostos de forma chocante (sendo alguns pisados pelos visitantes).

A revista Pontos nos ii (05-04-1888), por exemplo, dedicada à catástrofe, foi profusamente ilustrada com gravuras de Rafael Bordalo Pinheiro e uma com a lista dos donativos. A capa é dedicada ao maestro e à dor pela perda do seu filho. Nas páginas seguintes é possivel ver imagens dos corpos calcinados, em posições de desespero, assim invocando o sofrimento das vítimas e apelando à generosidade de todo o pais, mas também do estrangeiro, donde vieram mensagens de condolências.

\section{Uma memória menos luminosa}

Em 1908, Sousa Bastos publicou o Diccionário do teatro português, onde constam múltiplas entradas com referência ao Teatro Baquet e onde é possivel perceber que muitos actores ali se estrearam e/ou ali trabalharam. $\mathrm{Na}$ entrada referente ao Teatro Baquet (Bastos 1908: 267) podemos ver uma litografia do próprio autor, o que diz bem da marca que o incêndio do Teatro Baquet imprimiu nas memórias dos contemporâneos.

Embora seja perceptivel que o desenho teve como base a gravura de Nogueira da Silva, esta imagem é muito menos luminosa, não só devido à técnica utilizada, mas também porque nela não existe vida. É apenas uma espécie de fantasma do verdadeiro Teatro Baquet, com as linhas estilizadas de Nogueira da Silva diluídas pelo tempo (esborratadas pelas lágrimas?), com o objectivo de que a memória da catástrofe se não perca e sirva, talvez, de exemplo.

A gravura original do Teatro Baquet - de que parti permite, escavando, chegar à realidade dolorosa que se esconde por trás dela. Mas o Baquet foi muito mais importante para a História do Teatro por ter forçado a tomada de medidas drásticas, que melhoraram as condições de segurança. Na sequência do incêndio, as sessões da Câmara dos dignos pares e da Câmara dos Deputados, dos dias a seguir ao incêndio, tiveram como principal tema o Baquet, a ajuda às vítimas, o apurar de responsabilidades 


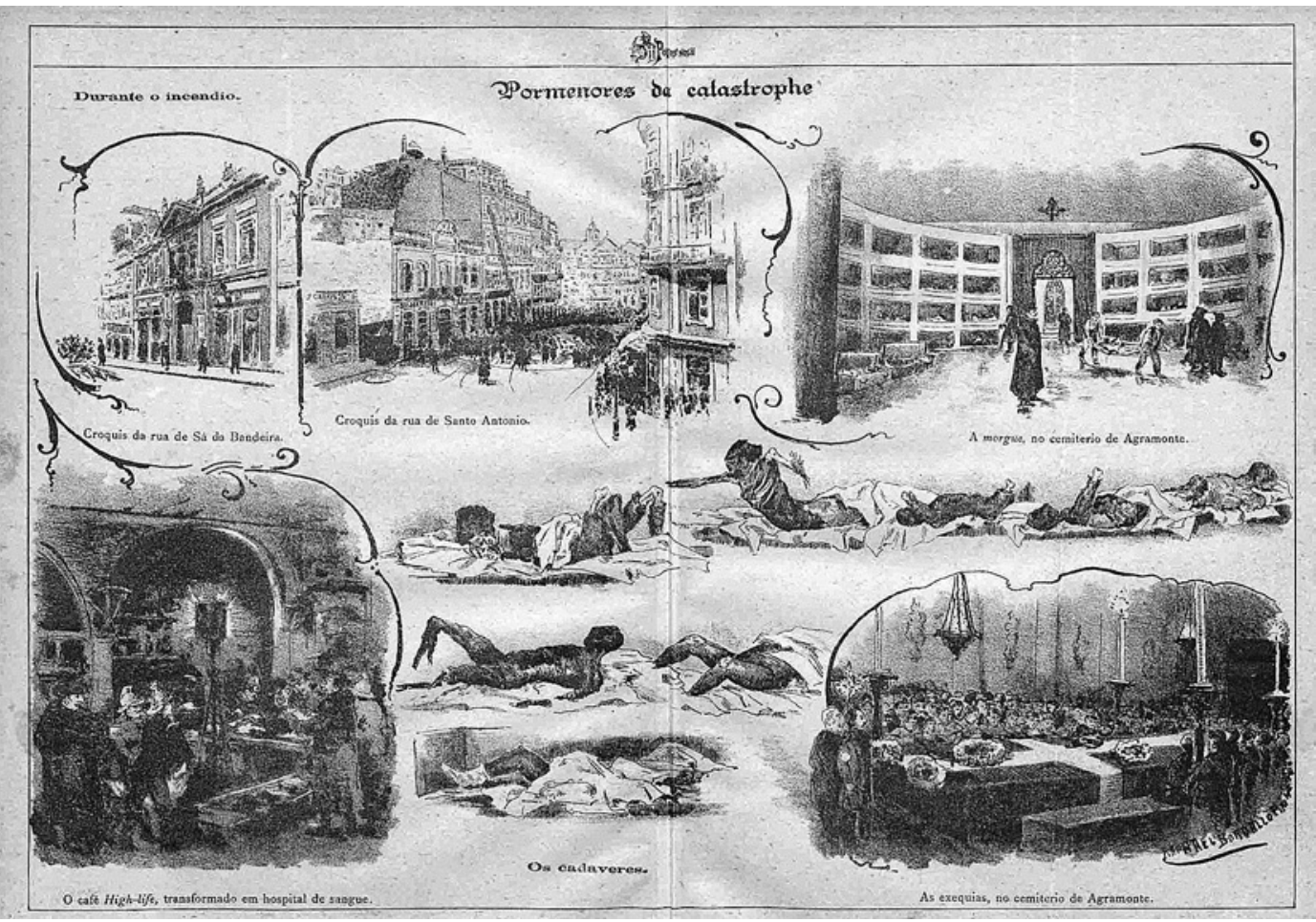

e a necessidade urgente de medidas e renovadas leis que evitassem novas tragédias. Há também o reconhecimento de que a não aplicação das anteriores potenciava as hipóteses de novas catástrofes, em qualquer dos teatros do pais.

A primeira questão debatida foi "determinar de modo preciso e claro a quem competia velar pela segurança das casas de espectáculos, se às câmaras municipais, se às autoridades administrativas, visto que o código não era claro nesse ponto" ${ }^{16}$ (Filinto 1888: 199), o que diz bem da anarquia e incúria reinante mas, sobretudo, da pouca importância dada às questões do Teatro, por parte das autoridades. No ano anterior, devido ao incêndio na Opéra Comique, em Paris, tinha sido nomeada uma comissão de engenheiros para verificar a segurança dos Teatros D.

Maria II e São Carlos, mas as medidas aconselhadas não tinham sido postas em prática, por temor de "censuras por efectuar despesas de luxo". 0 que antes não fora feito, era tomado como urgente na sessão de 22 de Março de1888 da Câmara dos Deputados, graças ao incêndio no Baquet.

Também graças ao incêndio na Opéra Comique, tinha sido feita uma vistoria a todos os teatros (o que motivara algumas alterações no Baquet, mas não todas as aconselhadas), facto com que se congratularam os deputados dizendo que, se assim não fora, a desgraça poderia ter sido ainda maior. No estrangeiro, o pano de ferro ou a tela de amianto - dificeis de manobrar raramente tinham sido utilizados em caso de tragédia, geralmente agravada pela asfixia por monóxido de carbono, desenvolvido pela combustão dos panos pintados. As propostas apontam para telas menos combustiveis, mas que ainda não tinham sido inventadas, concluem. Encontram uma medida mais eficaz que passa por "estabelecer galerias exteriores, correspondentes a cada uma das ordens de camarotes, ligadas umas às outras por escadas, despejando sobre a rua", como um Teatro que estava a ser construido na Bélgica, mas concordam em que só é possivel para construções novas. Às criticas de alguns deputados à incúria do Estado, por não ter acatado o parecer da comissão de 1887, foi respondido que se tinham feito novas saídas "para a plateia superior e [se] facilitara a saída da plateia geral " e também que já não havia um único bico de gás no Teatro São Carlos. Em relação a este teatro, é sugerida a expropriação do terreno anexo, para fazer uma arrecadação fora do teatro e executar-se o sistema de varandas de saída, anteriormente sugerido, mas apenas para dar saída "à gente do palco", surgindo no entanto de imediato a questão financeira, como impeditivo. É sugerido que o empresário feche o teatro durante um ano e que o subsídio - atribuído nesse periodo - seja utilizado "para atenuar a despesa" (Ibid: 203). Na impossibilidade de fechar todos os teatros problemáticos, o que deixaria os trabalhadores e suas famílias na miséria, foi decidido que se deveria melhorar o que existia e proibir as construções novas que não cumprissem todas as condições de segurança.

Na Câmara dos dignos pares de 23 de Março de 1888, depois de se lamentar o sucedido, discutiu-se essencialmente a questão do Teatro São Carlos, louvando as alterações efectuadas e propondo, também, a expropriação do terreno anexo para prover uma saída para os artistas, para além da disponibilidade total para aprovar " quaisquer providências do governo". Louvando as reformas efectuadas no Teatro do Príncipe Real, aconselharam a mesma exigência e rigor a todos os outros teatros e solicitaram ao governo uma lei definitiva sobre as construções teatrais e outra sobre o policiamento dos espectáculos ${ }^{8}$.

Em termos práticos, em 23 de Março de1888 é emitida pelo Ministério do reino uma portaria ordenando aos governadores civis diversas disposições sobre a segurança contra incêndios nos teatros e casas de espectáculos, (DG n. $\left.{ }^{\circ} 69,24-03-1888\right)$. Nela, por ter ardido o Teatro Baquet
${ }^{6}$ No regulamento de 1870, era claro ser da competência dos Governos Civis; com o alargamento das atribuições das câmaras em 1886, esta questão ficara obscura.

No Baquet não foi possivel tornar rectas as saidas - o que implicava uma rotação do palco de $180^{\circ}$ - devido ao conflito com o dono do café Highlife.

${ }^{8}$ Não deixa de ser irónico que um dos focos dos três incêndios anteriores no Baquet tenha sido um charuto aceso, deixado no chão do camarote da autoridade. 
do Porto, é chamada a atenção para as disposições da circular de 26 de Dezembro de 1881 sobre inspecção rigorosa a todos os teatros e casas de espectáculos ${ }^{9}$. No dia seguinte o mesmo Ministério nomeia uma comissão para formular um regulamento em que se estabeleçam as condições que devem observar-se quanto à polícia, higiene e segurança das casas de espectáculos existentes, e das que de futuro se construírem. (DG n. ${ }^{\circ} 125,02-06-$ 1888).

\section{No quintal do senhor Baquet}

Depois de ter acolhido o Teatro Baquet, uma belíssima sala de espectáculos, bem integrada no quotidiano da cidade, o quintal do senhor Baquet, limpo de destroços e cinzas humanas, encheu-se de vida com os luminosos Grandes Armazéns Hermínios, o primeiro dos estabelecimentos do género no pais, implantados no mesmo espaço. De construção ampla e majestosa, as paredes altas, janelas largas e grande clarabóia permitiam a entrada da luz e do ar, que faltaram aos que perderam a vida no incêndio do Baquet.

Actualmente, no lado da Rua de Sá da Bandeira, o mesmo espaço acolhe o Hotel Teatro, projecto vencedor do European Property Awards 2010, na categoria Best Interior Design Award, criado pela arquitecta Nini Andrade

${ }^{9} 0$ relatório final das inspecções aos teatros e casas de espectáculos do Porto foi publicado no DG

n. ${ }^{113}$, de 18-05-1888

(pp. 1083-1090)

e DG n. $114,19-05-1888$

(pp. 1098-1101)].

${ }^{10}$ http://www.hote teatro.pt/Galeria-deFotos-12.aspx

\footnotetext{
${ }^{11}$ No dia 31 de Janeiro
} de 1891 deu-se, no Porto, um primeiro movimento

revolucionário com o objectivo de implantar em Portugal o regime republicano. Em memória desta revolta, logo que a República foi implantada a Rua de Santo António foi rebaptizada Rua de 31 de Janeiro. Em 1940, com

o Estado Novo, a rua

voltou ao seu nome original, mas recuperou o

31 de Janeiro após a revolução de Abril de
Silva, que recupera a memória mítica e romântica deixada pelo Baquet. Todos os espaços do hotel são visivelmente teatrais, com cortinas múltiplas, adereços e guarda-roupa dispersos pelo espaço, formando verdadeiros cenários. A imagem mais forte, e muito presente em várias das imagens disponíveis online ${ }^{10}$,é uma foto gigante de uma plateia cheia de público que podia ser a do Teatro Baquet na noite do incêndio. A fachada que substituiu a do Baquet é espelhada, o que a torna invisivel e capaz de espelhar tudo o que nela se reflecte, como um imenso espaço vazio onde a cidade se inscreve. Palco de lazer, diversão e dramas ficcionais foi, ao mesmo tempo, cenário de uma catástrofe que passou a fazer parte do imaginário portuense.

Também a maqueta que recorda a Revolução de 31 de Janeiro ${ }^{11}$, exposta no Museu Militar, apresenta o espaço do Baquet de uma forma muito significativa: mais uma vez o vazio, uma ferida a céu aberto. Uma chaga aberta no coração da cidade.

\section{Fontes}

\section{Legislação}

Recolhida em 12.01.2012

http://www.panathlonlisboa.pt/index.php?option=com_contentEtview=a rticlectid $=51$ \&ttemid $=137$

\section{Sessões das Câmaras: Pares do Reino}

23-03-1888 http://debates.parlamento.pt/

diary.aspx? $c i d=m c . c p 2 \&$ tnum $=\&$ tdate $=1888-03-23$

24-03-1888 http://debates.parlamento.pt/ diary.aspx?cid=mc.cp2\&tnum $=\varepsilon$ tdate $=1888-03-24$ 27.03.1888 http://debates.parlamento.pt/ diary. $a s p x ? c i d=m c . c p 2 \&$ tnum $=\&$ tdate $=1888-03-27$

\section{Senhores Deputados}

23.03.1888 http://debates.parlamento.pt/ diary. aspx? $\mathrm{cid}=$ mc.cd\&num $=$ \&tdate $=1888-03-23$ 24.03.1888 http://debates.parlamento.pt/ diary.aspx?cid $=$ mc. cd\&num $=\varepsilon$ tdate $=1888-03-24$ 26.03.1888 http://debates.parlamento.pt/ diary.aspx? cid $=$ mc.cd\&tnum $=$ \&tdate $=1888-03-26$ 27.03.1888 http://debates.parlamento.pt/ diary.aspx? $c i d=m c . c d \&$ tnum $=$ \&tdate $=1888-03-27$

\section{Referências bibliográficas}

BASTOS, Sousa (1898), A carteira do artista, Lisboa, Antiga Casa Bertrand - José Bastos

-- (1908), Diccionario do theatro portuguez, Lisboa, Imprensa Libanio da Silva.

BORDALO-PINHEIRO, Rafael (1888), Pontos nos ii, ano IV, 5 de Abril, pp 513-520 (número especial dedicado ao Baquet).

FILINTO, Jayme (1888), A grande catastrophe do Theatro Baquet narrativa fidedigna do terrivel incêndio ocorrido em a noite de 20 para 21 de Março de 1888, precedida da história do Theatro, Porto, Casa Editora Alcino Aranha \& Ca.

LOBATO, Gervásio.(1888), "Chronica occidental" in O ocidente, Lisboa, vol. $\mathrm{XI}, n^{\circ} 334,11^{\circ}$ ano, Abril.1888: pp. 74-75 e vol. XI, $n^{\circ}$. 353, $11^{\circ}$ ano Outubro.1888: 217-218

OLIVEIRA, Paulo Martins (2009), Elementos para a história da gravura e da fotografia em Portugal / e II. (O PDF recolhido online, em 2010, onde já não se encontra disponivel)

RIGAUD, João-Heitor (2009), o Porto e a música, s/l, Artigos Meloteca.

\section{Referências sitiográficas}

AFONSO, Graça (2007), O Archivo pittoresco e a evolução da gravura de madeira em Portugal. (Recolhido em 02-02-2012 em http://hemerotecadigital.cm )lisboa.pt/Recursos Informativos/EstudosInternos/ArquivoP/ArchivoPGravura.pdf)

ALMEIDA, Marcelina das Graças de (s/d), "Teatro Baquet: memória e ruinas" (Recolhido em 01-12-2012 em www.geocities.ws/adarantes/ textos_marcelina/2.doc)

BARBOSA, I. de Vilhena, (1863), "Porto - Teatro Baquet", Arquivo pitoresco, vol. VI, Lisboa, Editores proprietários Castro Irmão \& c ca. Lda, p. 257. (Recolhido em 02-02-2012 em http://books.google.com/books?id= W9hGAAAAMAAJ\&tprintsec $=$ frontcover\&thl $=$ ptPT\&tsource $=g b s \_g e$ summary_retcad $=0 \# \mathrm{v}=$ onepagectq\&tf=false

DIAS, Eurico (2007), "Archivo pittoresco (1857-1868). Subsidios para sua história" (Recolhido em 02-02-2012 em http://hemerotecadigital.cm lisboa.pt/RecursosInformativos/EstudosInternos/ArquivoP/ConfArq Pit.pdf 


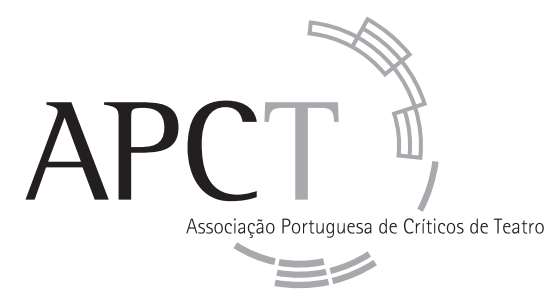

\begin{tabular}{l|l} 
Direcção & $\begin{array}{l}\text { Maria Helena Serôdio } \\
\text { João Carneiro } \\
\text { Rui Pina Coelho }\end{array}$
\end{tabular}

Assembleia Geral

Alexandra Moreira da Silva

Sebastiana Fadda

Conselho Fiscal

Ana Isabel Vasconcelos

Mónica Guerreiro

Rita Martins

Capitulo Primeiro (Da Associação e dos seus fins)

ESTATUTOS

Art. ${ }^{2} .^{\circ}$

A Associação tem por objectivo:

Dignificar, estruturar e responsabilizar a actividade crítica relativa à teoria e prática do teatro, entendendo-se por actividade crítica não só a crítica de espectáculos, mas também tudo aquilo que diga respeito à informação, reflexão e teorização no campo das artes performativas.

\section{Colaboração com Sinais de cena}

A revista está aberta à participação de quem deseje colaborar enviando artigos que julgue corresponderem aos objectivos da publicação e às modalidades enunciadas pelas rubricas existentes. A consulta do sítio da APCT na Internet (www.apcteatro.org) e o contacto por correio electrónico (estudos.teatro@fl.ul.pt) são indispensáveis para conhecer as normas de apresentação dos artigos (dimensão, aspecto gráfico, citações, referências bibliográficas, ilustrações, etc.).

\section{ASSINATURA}

Desejo subscrever os números 19 e 20 da revista Sinais de cena (correspondentes a Junho e Dezembro de 2013), no valor total de $22,00 €$ beneficiando assim de um desconto sobre o preço de venda ao público. Fora do país: Europa $24,00 €$ / Fora da Europa $26,00 €$

Nome:

Morada:

Código postal: $\quad$ Pais:

Endereço electrónico:

\begin{tabular}{l|l|l|} 
Forma de pagamento: $\quad \square$ Vale postal $\quad \square$ Cheque $n^{\circ}$. & Banco \\
\hline
\end{tabular}

(passar à ordem de Associação Portuguesa de Críticos de Teatro)

Preencha e envie este cupão (ou fotocópia do mesmo) para:

Data:

\section{Sinais de cena}

Centro de Estudos de Teatro

Faculdade de Letras de Lisboa: sala 67

Alameda da Universidade

1600-214 Lisboa (Portugal) 
